\title{
Effective Communication Following Pregnancy Loss: A Study in England
}

\author{
LOUISE AUSTIN, JEANNETTE LITTLEMORE, SHEELAGH MCGUINNESS, \\ SARAH TURNER, DANIELLE FULLER, and KAROLINA KUBERSKA
}

\begin{abstract}
Each year in the UK there are approximately 250,000 miscarriages, 3,000 stillbirths and 3,000 terminations following a diagnosis of fetal-abnormality. This paper draws from original empirical research into the experience of pregnancy loss and the accompanying decisionmaking processes. A key finding is that there is considerable variation across England in the range of options that are offered for disposal of pregnancy remains and the ways in which information around disposal are communicated. This analysis seeks to outline the key features of what constitutes effective communication in this context, where effective communication is taken to mean that patients are provided with the key information necessary, in an appropriate manner, so that they are fully able to make a decision. A primary source of evidence includes interviews with the bereaved and pregnancy-loss support workers, in order to understand how the options available, and associated necessary procedures, are communicated. In addition, patient information leaflets are also analyzed as they offer an important tool for information delivery at a difficult and emotionally charged time. Following this, an overview is provided of the information that these leaflets should contain, along with guidance on effective presentation of this information.
\end{abstract}

Keywords: pregnancy loss; pregnancy remains; informed consent; effective communication

\section{Introduction}

Each year in the UK, there are approximately 250,000 miscarriages, 3,000 stillbirths, and 3,000 terminations following a diagnosis of fetal abnormality. ${ }^{1}$ Pregnancy loss is often a difficult experience, and both the emotional and psychological impacts of miscarriage have been identified as a priority area for future research. ${ }^{2}$ Bereavement following pregnancy loss engenders complex emotions, due to its status as a deeply embodied experience, involving the loss of a life not yet lived. The difficulties can be compounded as usually these losses are not planned and as such suddenly give rise to the need to make previously unforeseen decisions. The psychological and emotional impacts of miscarriage are often under-recognized. ${ }^{3}$ The subject is not widely discussed in British society ${ }^{4}$ and there is a lack of cultural scripts for dealing with perinatal bereavement. ${ }^{5}$

Moreover, in pregnancy loss, a baby dies before it is born and, therefore, occupies a liminal status. Those who have experienced the loss may be uncertain as to what options are available regarding disposal (including, e.g., burial or cremation). ${ }^{6}$ For this reason, it is important that they are informed clearly of the complete range of options available to them. ${ }^{7}$

Acknowledgements: We are grateful to Patrick Dandy for research input. We would like to thank Thomasine Kushner and Mary Varney Rorty for helpful feedback and editing of earlier drafts of this paper. We acknowledge the support of the ESRC in funding the "Death Before Birth" project (award number: ES-N008359-1). Finally, we would like to thank the project participants and our project partners. Further details of the project can be found here: https:// deathbeforebirthproject.org/ 
By drawing on original empirical research into the experience of pregnancy loss and the accompanying decisionmaking processes, this paper explores the ways in which the options for disposal are presented to the bereaved following pregnancy loss. In order to understand how the available options and associated procedures are presented, a primary source of evidence includes interviews with a sample of both bereaved individuals and pregnancy-loss support workers. In addition, patient information leaflets are also analyzed as they offer an important tool for information delivery at a difficult and emotionally charged time.

The analysis presented in this paper forms part of a larger project, the "Death Before Birth" (DBB) project. ${ }^{8}$ This was a socio-legal, linguistic study of how people in England who have experienced miscarriage, termination, and stillbirth reach decisions concerning the disposal of the remains of pregnancy, how their perceptions of the law impact their decisionmaking and how they communicate their experiences and choices to those who support them. ${ }^{9}$ Findings from DBB evidence: (1) that there is considerable variation across England in the range of options that are offered $^{10}$ and (2) that people report effective communication as being important in shaping their experiences. ${ }^{11}$ We use our own empirical research from this project to explore the ways in which the options for disposal were communicated to women who had experienced pregnancy loss. We bring these analyses together to provide as comprehensive an overview as possible of what might constitute effective (and less effective) communication with patients at a time of loss. Effective communication is taken to mean that patients are provided with the key information necessary, in an appropriate manner, in order to ensure they are fully able to make a decision about the disposal of pregnancy remains and any accompanying ceremonies. This definition reflects the current legal standard of information provision in the context of informed consent to medical treatment, as set out in Montgomery $v$ Lanarkshire Health Board, discussed in more detail below. ${ }^{12}$ In this paper, we unpack this definition of information provision and explore the implications of good and bad communication in relation to the presentation of options for disposal following pregnancy loss.

When pregnancy loss occurs, it is important that the bereaved are provided with full information about the choices available to them regarding disposal of pregnancy remains, including any possible ceremony or funeral. ${ }^{13}$ In England, the permissible options for disposal are burial, cremation, sensitive incineration, or burial on private ground. One interviewee in the DBB Project, a volunteer with a support organization, summarized how absence of information can lead to confusion about what options are available, or a feeling that there is a lack of choice as to what they can do:

\footnotetext{
"I've heard people say 'Well, what seems to be on offer is this kind of group cremation'. They've said, 'I don't know if we've got the choice to do anything different, and maybe we'll want to do something different'. People don't always seem very clear on their options." [Pregnancy-loss support worker]
}

Not only is it important to provide sufficient information, this information must also be communicated sensitively in a patient-centered manner. The impact of language and communication on the experiences of the bereaved following pregnancy loss 
cannot be overstated. For this woman, the means of communication was one of the most significant aspects of her experience:

\footnotetext{
"It's a learning experience and the language around it is just so poor. That's what I've definitely learned throughout this whole ordeal." [Participant who experienced stillbirth]
}

Our findings evidence a lack of standardization across England both with regard to the information with which patients are provided, and also with regard to how this information is communicated. ${ }^{14}$ Two key guidance documents, produced by the Human Tissue Authority (HTA) and the Royal College of Nursing (RCN), set out the range of permissible options for disposal which staff should discuss with patients. ${ }^{15,16}$ In addition, the Stillbirth and Neonatal Death Charity (Sands) and the Institute of Cemetery and Crematorium Management (ICCM) provide information about the sorts of funerals or ceremonies which may accompany certain disposal options; specifically, burial and cremation. ${ }^{17}$

To address the deficiencies in communication described above, we (1) explore characterizations of effective communication according to the HTA Guidance and how the bereaved, and those who support them, experience it; (2) consider how the information is presented by healthcare professionals and in the patient information leaflets, an important adjunct for information delivery, especially at a difficult and emotionally charged time; and (3) provide an overview of the information that these leaflets should contain along with some guidance on how this information should be presented. We focus on what the participants explicitly said about "communication," including the impact of "effective communication on their experience of care." ${ }^{18}$ We analyzed all the places where our participants described provision of information in order to identify what they deemed to be "good" communication and what they deemed to be "poor" communication.

\section{Background and Research Methods}

As mentioned above, our project took advantage of results of the DBB project, a 2-year ESRC-funded study running from 2016 to 2018 and granted ethical approval by the University of Birmingham. In the first stage of the project, hospital documentation from 54 National Health Service (NHS) Trusts from across the four regions of NHS England was analyzed to determine what information patients were being given at the time of pregnancy loss regarding options for disposal of pregnancy remains, including details of any accompanying ceremonies. Following this documentary analysis, we undertook semi-structured interviews of 60-90 min in length. The breakdown for these interviews was as follows:

- We conducted 12 interviews with 18 bereavement care providers, the majority of whom were bereavement care midwives recruited directly from hospitals across four NHS regions (London/the South/the Midlands/the North). In these interviews, we explored their views on the support they offered and the procedures they used.

- Fifteen funerary practitioners, the majority of whom were funeral directors, were recruited from across England, in order to gain insights into some of the practicalities involved in funerals and cremations. 
- Eighteen individuals who provide support for the bereaved, many of whom had themselves experienced pregnancy loss.

- Thirty-five people who had experienced miscarriage, termination due to fetal abnormality (hereafter referred to as "termination") or stillbirth a minimum of 6 months before the interview. Of these 35, the majority were women, but 3 were male partners and 1 was a friend of a bereaved participant. These participants were recruited from across England through adverts promoted by our partner organizations (Sands, Miscarriage Association, and Antenatal Results and Choices). During the interviews, we explored the participants' experiences of pregnancy loss, focusing on what they did with the pregnancy remains, how they reached their decisions, and the emotional effects of their loss.

The interviews were face-to-face when possible, or otherwise conducted via skype or by telephone. The interviews were audio-recorded, transcribed and then uploaded into NVivo, a qualitative research package used to assist in data organization and annotation using a set of user-defined categories, for coding. For our analysis, we focused on the parts of the interviews in which participants explicitly spoke about their experience of the loss, their ways of dealing with it, the choices they made regarding memorialization and remembrance, and the reaction of other people to their loss. Among the 81 topics identified, among the most frequently discussed by participants included: "the diagnosis," "memory-making," "recovery," and "communication."

The documentary analysis and the interviews conducted as part of the DBB project revealed that those who experience miscarriage are typically offered information about some, but not all, of the permissible options for disposal, most frequently cremation. ${ }^{19}$ It also evidenced a range of practices with regard to the means of communication of this information.

\section{Pregnancy Loss and Effective Communication in Decisionmaking}

Effective communication involves the provision of key information in an appropriate manner to support the patient's decision. ${ }^{20}$ We start by providing an overview of the legal standard for appropriate information provision as laid out in Montgomery $v$ Lanarkshire Health Board and then move on to detail what the effective operationalization of this standard looks like in practice. ${ }^{21}$

\section{The Legal Standard}

Decisions arising from pregnancy loss are a mix of clinical (e.g., decisions as to whether to elect for medical or expectant management of miscarriage) and nonclinical decisions (e.g., how the pregnancy remains should be disposed of). When patients are participating in clinical decisionmaking Montgomery sets out criteria for determining what information people should be given in order to make an informed decision. In this case, the United Kingdom Supreme Court concluded that with regard to information provision, the doctor's duty was:

[...] to take reasonable care to ensure that the patient is aware of any material risks involved in any recommended treatment, and of any 
reasonable alternative or variant treatments. The test of materiality is whether, in the circumstances of the particular case, a reasonable person in the patient's position would be likely to attach significance to the risk, or the doctor is or should reasonably be aware that the particular patient would attach significance to it. ${ }^{22}$ [Emphasis added]

When giving her concurring opinion in Montgomery, Baroness Hale stated that the interest that informed consent seeks to protect "is a person's interest in their own physical and psychiatric integrity, an important feature of which is their autonomy, their freedom to decide what shall and shall not be done with their body." ${ }^{23}$ Louise Austin and Sheelagh McGuinness have argued that since the boundary between clinical and nonclinical is not easily drawn, the disclosure obligations in Montgomery extend to the nonclinical elements of decisionmaking in pregnancy loss, including disposal of pregnancy remains. ${ }^{24}$

Neil Manson and Onora O'Neill have previously argued that to set feasible standards in informed consent, there are epistemic and ethical norms which informed consent as a communicative transaction must meet in order to be successful. Such norms include the need for information to be intelligible, accurate, relevant, and honest. ${ }^{25}$ Montgomery echoes this emphasis on the importance of actual communication in information provision by requiring doctors to engage in dialogue with patients in order to ensure the patient understands the information given. ${ }^{26}$ What amounts to effective communication beyond dialogue and patient understanding is not addressed in Montgomery. As Rob Heywood and José Miola have stated Montgomery contains "[...] guidance on what the doctor's duty does not consist of, but less regarding what is required [...] In particular, there is no mention at all of the mechanics of communication." 27 The only guidance given in Montgomery is that the duty of a healthcare professional (HCP) is not "fulfilled by bombarding the patient with technical information which she cannot reasonably be expected to grasp" [Emphasis added]. ${ }^{28}$ Our findings draw from patient experience to gain insights into what constitutes effective communication and thus facilitates informed consent in the context of reproductive loss.

\section{Patient Perceptions of Effective Communication}

The bereaved parents we interviewed reported both effective and ineffective communication following pregnancy loss, and described the effect this communication had on their emotional state and their decisionmaking processes.

\section{Sufficient Information}

A starting point for effective communication is the provision of sufficient information to facilitate an informed decision. With regard to disposal and funerals, according to key guidance documents patients should be told that the following options are permissible:

- Burial [shared/ individual]

- Cremation [shared/ individual]

- "Sensitive" incineration

- Burial on private land (often at home) 
- Supported in making their own arrangements ${ }^{29}$

In addition to this, they should be provided with details of:

- Any ceremony that accompanies cremation or burial (e.g., whether there will be songs/prayers/readings)

- Whether parents can attend the ceremony

- Costs

- Whether ashes will be available and what will be done with the ashes

Our findings evidence clear gaps in information. Some participants described feeling that they were not given sufficient information and consequently had inaccurate expectations of their options for disposal of pregnancy remains:

"[We were told] that it'll go to the crematorium and you'll get invited to what they call a service where all the babies basically get cremated together. We never heard anything. They never contacted us, never told us when it was happening." [Participant who experienced miscarriage]

"They say that when it happens, apparently they play nursery rhymes?" [Participant who experienced miscarriage]

The standard of information provision in patient information leaflets also varied. Although many of the patient information leaflets provided the information clearly, in some cases, the information was presented in a vague manner, making it somewhat difficult to understand and, therefore, failing to meet the criteria of intelligibility identified by Manson and O'Neill. For example:

\footnotetext{
"You may wish to have your baby at home for a short time before the funeral, or to visit your baby in the Chapel of Rest at the funeral directors. Sometimes funeral directors advise against this, but it is important to talk this over with them...take time to reach your decision - again, nothing need be rushed." (Information for Bereaved Parents)
}

Here, it is unclear why funeral directors might advise against "this," what "this" refers to (having the baby at home or visiting the baby in the Chapel of Rest), and what exactly should be discussed. Although it is commendable that the leaflet recognizes the importance of making the choice that is right for the bereaved, and the need to have time to make decisions, clearer language at this point is likely to be beneficial. It is also unclear on what basis parents should be discouraged from bringing the remains home as this is potentially important to the bereavement process. The following are examples of clear, detailed information on the choices available:

\footnotetext{
“The hospital uses a special area at the local [NAME] Cemetery for all our baby funerals. Your baby will have his or her own coffin with a name plaque on and will be buried in a communal grave with up to 16 other babies." (Information leaflet for parents after death or stillbirth of a baby)

"You may wish to bury your baby's remains at home. The garden may seem like the obvious place as long as it is your own garden. This may not
} 
be the best option if you are planning to move in the future or it is a rented house or shared space. You are advised to bury the remains at a depth of approximately 18 inches $(45 \mathrm{~cm})$ to prevent unearthing by animals. You may wish to put a stone slab on top to prevent this happening. The burial site should not be close to a water source." (Information Leaflet on Burial Advice Following a Pregnancy Loss)

\section{The Needs of the Particular Patient}

What counts as sufficient information will vary from person to person and it is important that information be provided in a patient-centered fashion that responds to the needs of the particular person to whom the HCP is providing care so that the information meets the criteria of relevance identified by Manson and O'Neill. Montgomery's inclusion of consideration of the particular patient within the legal standard of disclosure highlights the need to tailor information provision to the individual. Patient information leaflets, however, usually have a standardized format. The sole reliance on standardized leaflets has been criticized as they risk de-individualizing care ${ }^{30}$ and do not take account of differences in literacy skills. ${ }^{31}$ Therefore, the provision of patient information leaflets should be seen as one of the necessary methods used to support dialogue between patients and clinicians, rather than as the sole method of communicating information effectively. ${ }^{32}$

Effective communication means avoiding making assumptions about how people may be feeling following a loss. This will vary from person to person; what counts as overly emotive or inappropriate language for one individual may be an accurate description of how another is feeling. Participants in our sample spoke of assumptions being made about how people were feeling and how they would like to proceed. This is demonstrated in the following quotation where a bereaved parent talks about her feelings toward the memory box she was offered:

"Did the hospital offer anything like a certificate to mark the birth and death of your son?" [Interviewer]

"Yeah they did. And they gave us a memory box. The memory box was a bit cheesy really. Didn't like it. It was full of stuff to do with angels. We're atheists. So we found that a bit shitty, to be honest. I don't really buy into the whole angel baby thing. To me it's mawkish. It doesn't fit with my value system. So I didn't like all the angel stuff." [Participant who experienced miscarriage]

The two extracts below, both of which are from information leaflets about making funeral arrangements, demonstrate variation in the way the information is presented to parents:

"Making funeral arrangements is a deeply upsetting and stressful event of which bereaved parents may have no previous experience."

"Arranging your baby's funeral yourself can be empowering and healing."

In the first extract, the language is both rather overly-dramatic and assumptive. It appears somewhat foreboding, implying that parents will certainly find the arrangements distressing and difficult. In contrast, the language in the second extract softens the statement using the word "can," thereby allowing room for a 
range of different experiences. In this second extract, the focus on the potential positive aspects, too, is likely to be comforting for parents. Another example of problematic framing that arose in leaflets we examined was the referral to the funeral as being "the final act for your baby." This sounds both formal and categorical. It also seems to dismiss the potential for future memory-making acts, such as marking anniversaries and other important dates in the future, which parents may find helpful.

To conclude this section, although empathy is likely to be appreciated in information provision, it is important that this is done in such a way that allows room for a range of emotions and reactions. The easiest way to accomplish this goal is through the use of phrases such as can, may, or could.

\section{Directive Language}

Information should be presented in a nondirective manner in order to ensure that parents are able to make the decision that most suits them. However, some participants felt that medical staff were being overly directive, and that the bereaved therefore felt that they were being pushed to take a particular option:

"I felt very much that my hands were almost tied, that. . they were sort of
pushing me to go down the medical route [...] So I[m] to this day still
scratching my head as to why he felt that he had to sort of push me in one
direction." [Participant who experienced a termination due to fetal-
abnormality]

Similarly, in some of the leaflets, one option was presented much more forcefully than the others, without any explanation. This gave the impression that they were promoting one particular choice of disposal of remains. This was sometimes achieved by presenting information in a subtly directive way, implying that there is a "normal" way to do things. This is done through the use of words such as "most," as can be seen in the following example:

"Most women (and their partners) choose to let the hospital deal with the
disposal of remains." (Information leaflet on disposal of pregnancy
remains)

This use of the word "most" implies that if they do not make this choice, they may find themselves in the minority and thus, the "most" becomes subtly coercive. In this case it might have been better to employ a word such as "many" or "some."

Another example of how language can be directive, even if unintentionally, is in how different options are presented as compared to each other. For example, in one leaflet, cremation was emphasized more strongly than all the other options. This was done through the use of different modal verbs, such as "will" and "would" and in the ordering of the options on the page. The first option to be presented is cremation:

\footnotetext{
"Remains chosen for cremation will be sent in vessels to the [NAME] Crematorium for cremation and dispersal of the ashes in the garden of remembrance. There will not be any memorial or returnable ashes. You may wish to make your own arrangements for a private cremation."
} 


\title{
Bioethics Beyond Borders
}

The second option is burial:

"You may wish to make your own arrangements for a private burial. Burial is only offered in a shared plot for specific religious reasons and will need to be discussed with the chaplaincy."

The third option is taking the remains away to make one's own arrangements:

\begin{abstract}
"You may wish to consider taking the remains to make your own cremation or burial arrangements. If this is your choice the Institute of Cemetery and Crematorium Management (ICCM) can provide you with additional information on this choice. If you request that, the remains would be stored in an appropriate container in a safe place and made available for collection by you or your representative. The decision, and the date of collection, would be recorded in your notes and you would be given written confirmation that you are entitled to take the remains to make your own arrangements. You will be expected to sign a form before taking the remains with you." (Information leaflet on disposal of pregnancy remains of less than 24 weeks gestation)
\end{abstract}

As we move through the three options, we see that the modality becomes increasingly less strong, which suggests that the apparently "favored" option (cremation) is being presented more forcefully than the other two options. In the description of the third option (taking the remains away), the only use of "will" relates to the fact that the parents will be expected to sign a form. There, therefore, appears to be an implicit bias toward cremation.

Effective communication should consist of nondirective, patient-centered language that facilitates bereaved parents in making the decision that is best for them, including providing suggestions that make it very clear that a choice is being offered where this is appropriate. Consider the following examples from leaflets on funerals:

"First and foremost, this was your baby, and you have the right to make arrangements for the funeral yourself." (Information on Baby Funerals)

"You may also like to give each person a little memento such as:

A packet of forget-me-not seeds for those present to plant in remembrance of your baby.

A sprig of rosemary-the herb of remembrance

A single white bloom

A small candle $[\ldots]$

You might also like to consider having your child laid to rest in a family grave with a grandparent or great-grandparent."

Here, it is good to see that the parents are being made aware of a range of symbols that they might use to memorialize their baby and that this is not a limited choice. Also, the idea that the baby can be buried with a grandparent may be something of which parents might not otherwise be aware.

\section{"Bombarding the Patient...."}

Many parents appreciated clear and non-directive information on all the options available to them, although it was important that this information was delivered in a 
way that was not overwhelming. When receiving a diagnosis of miscarriage or stillbirth the parent is likely to be in a state of shock that impacts upon their ability to process information effectively:

\begin{abstract}
"I think it's quite hard because you have that massive shock, and your brain shuts down. and I couldn't process it. I knew they needed to tell me that then because of the nature of it. I knew that you couldn't wait ... I don't even know if she explained it really well ...my brain was obviously still in shock mode by then. The sonographer, she basically gave us a file and told us where to go but I think would've been nice if she'd said. . ' You will now be going to the early pregnancy unit; they are going to have other people there with scans, which I'm really sorry. . . but it's just we don't have resources. Once you go there the lady or man. . . will explain to you what has happened.'" [Participant who experienced miscarriage]
\end{abstract}

Thus, although patients and bereaved individuals need to have all the information available to them, HCPs should ensure that this information is delivered in an intelligible way as identified by Manson and $\mathrm{O}^{\prime}$ Neill. Patient information leaflets can be crucial in this respect, as they constitute a way in which the bereaved can access the information at their own pace and remind themselves of what they were told. As this bereavement midwife tells us:

"The family needs adequate information. We understand that when you
lose a baby initially you are in a state of shock, grief, sadness and denial.
You cannot be $100 \%$ sure that they absorb all the information, so we
provide written information." [Pregnancy-loss support worker]

\title{
Using Technical Language
}

Participants described conversations in which HCPs used language that was difficult to understand, either because it was vague, unclear, or euphemistic, or because there was an overreliance on medical terminology with insufficient explanation as to what the terms meant. Such language may be perceived as dysphemistic (i.e., overly clinical and harsh) as well as being unintelligible to the patient. Consider the following parents' accounts:

“The EPU [Early Pregnancy Unit] nurse said 'I don't really want you to have a natural miscarriage now because I think it would be quite horrendous.' That's all she said. So I said, 'Well, how does that happen? What do you do to stop it?' She said 'We can't.' I think that was really scary because I was, like, 'so if the baby does come away naturally, when you say you don't really want that, why? Why don't you want that?' She was just like, 'Well, it won't be very nice for you both.' She said I wouldn't really want that because of how long the baby had been inside me not alive, and I don't know really what that meant." [Participant who experienced miscarriage]

\footnotetext{
"In my letter from my consultant, they write to you afterwards, she put in something like "the remains of evacuation of uterus" and things like that. I thought 'what are you talking like that for?'" [Participant who experienced a termination due to fetal-abnormality]
} 
With regard to disposal of pregnancy remains, examples of the use of technical terms in the patient information leaflets without explanation included:

- a reference to the need for burial to "take place in an approved burial ground or cemetery" without explaining what "approved" meant;

- disposing of tissue in a "sensitive manner" without explaining what form that disposal would take;

- references to placing remains in a "vessel" or an "appropriate container" with no explanation as to what that container may look like.

Using technical explanations can lead to a disconnect between what the person experiencing the loss is expecting to happen and what occurs in practice.

\section{Conclusion}

Our research carried out as part of the DBB project suggests: (1) that there is a wide variation across England in the range of disposal options offered to people experiencing pregnancy loss and the ways in which that information is communicated and (2) effective communication is an important part of shaping people's experience of pregnancy loss. This reflects Manson and $\mathrm{O}^{\prime} \mathrm{Neill}^{\prime}$ s conclusions about the importance of communication in information provision, and the law's current emphasis on the importance of communication in informed consent as set out in Montgomery. However, despite effective communication being crucial to the experience of pregnancy loss, it is often neglected.

In order to offer insights into how information about pregnancy loss can be effectively communicated, this article has drawn upon the experiences of participants in the DBB project, and an analysis of patient information leaflets to identify examples of good and bad communication, providing a more nuanced account of what effective communication entails in this context. In order for information about pregnancy loss to be communicated effectively it must: address all options for disposal; be accurate and clear; be tailored to the needs of the individual patient; and avoid using directive or technical language, or language that makes assumptions about how people may be feeling about the pregnancy loss. This reflects the ethical norms with which Manson and O'Neill say communicative transactions in information provision should comply: intelligibility, accuracy, relevance, and honesty.

Following Montgomery, we argue that dialogue with the patient should be the primary method of communication of information. This requires a two-way discussion between the person experiencing the pregnancy loss and the healthcare professional. The discussion should aim to identify what information the person wants, and to communicate this information in a way that supports decisionmaking. Patient information leaflets can be a useful communication tool to supplement such dialogue by providing patients with information they can take away and process in their own time. Giving patients time to review and reflect upon information can contribute to their understanding of all the information they have been given, whether verbally or in written form.

The findings from our research illustrate why it is important that we get communication right when people have experienced pregnancy loss. Poor communication can have a negative impact on people's experience of pregnancy loss, exacerbating what may already be an emotionally distressing experience. We hope 
that the examples of effective communication given in this paper offer insights into how HCP scan communicate the options effectively. We also hope that our findings illustrate how patient information leaflets around pregnancy loss and disposal can be drafted in a way that allows effective communication of the options available, thus improving the potential effectiveness of these leaflets as an adjunct to dialogue.

\section{Notes}

1. Overview: Miscarriage. NHS: 2018; available at www.nhs.uk/conditions/miscarriage/\#how-com mon-are-miscarriages (last accessed 18 Jul 2019).

2. Prior M, Bagness C, Brewin J, Coomarasamy A, Easthope L, Hepworth-Jones B, et al. Priorities for research in miscarriage: A priority setting partnership between people affected by miscarriage and professionals following the James Lind alliance methodology. British Medical Journal Open 2017;7 (8):1-8.

3. Lok IH, Neugebauer R. Psychological morbidity following miscarriage. Best Practice and Research Clinical Obstetrics and Gynaecology 2007;21(2):229-47.

4. Peel E, Cain R. 'Silent' miscarriage and deafening heteronormativity: A British experiential and critical feminist account. In: Earle S, Komaromy C, Layne L, eds. Understanding Reproductive Loss: Perspectives on Life, Death and Fertility. Aldershot, UK: Ashgate; 2012:79-92.

5. See note 4, Peel, Cain 2012, at 79-92.

6. Kuberska K, Fuller D, Littlemore J, McGuinness S, and Turner S. (in press). Death before birth: Liminal bodies and legal frameworks. In: Dietz C, Thomson M, and Travis M, eds. Jurisprudence of the Body. London: Palgrave Macmillan; forthcoming.

7. Austin L, McGuinness S. Reproductive loss and disposal of pregnancy remains. Northern Ireland Legal Quarterly 2019;70(1):131-53.

8. Understanding, informing and supporting choices made by people who have experienced miscarriage, termination and stillbirth. Death Before Birth: 2017; available at https:/ / deathbeforebirthpro ject.org/ (last accessed 16 Jul 2020) (ESRC, ES-N008359-1).

9. About the project. Death Before Birth: 2017; available at https:/ / deathbeforebirthproject.org/about/ (last accessed 16 Jul 2020).

10. McGuinness S, Kuberska, K. Report to the Human Tissue Authority on disposal of pregnancy remains (less than 24 weeks' gestational stage); 2017; available at https:/ / deathbeforebirthproject. org/research/htareport2017/ (last accessed 16 Jul 2020).

11. Littlemore J, Turner S. What metaphor can tell us about the experiences of pregnancy loss and how these experiences are reflected in midwife practice. Frontiers in Health Communication 2019;4:42-59.

12. Montgomery $v$ Lanarkshire Health Board [2015] UKSC 11; available at https: / / www.supremecourt.uk/ cases / docs/uksc-2013-0136-judgment.pdf (last accessed 16 Jul 2020).

13. See note 7, Austin, McGuinness 2019.

14. See note 10, McGuinness, Kuberska 2017.

15. Human Tissue Authority. Guidance on the Disposal of Pregnancy Remains Following Pregnancy Loss or Termination; London: Human Tissue Authority; 2015.

16. Royal College of Nursing. Managing the Disposal of Pregnancy Remains; 2018.

17. Institute of Cemetery and Crematorium Management. The sensitive disposal of fetal remains: Policy and guidance for Burial and Cremation Authorities and Companies 2015. Sands Stillbirth and Neonatal Death Charity. Funerals and sensitive disposal. In: Pregnancy Loss and the Death of a Baby: Guidelines for Professionals, 4th ed. London: Tantamount Press, 2016:323-53.

18. Littlemore J, Turner S. Metaphors in communication about pregnancy loss. Metaphor and the Social World (in press); See note 11, Littlemore, Turner 2019.

19. See note 7, Austin, McGuinness 2019.

20. See note 7, Austin, McGuinness 2019.

21. See note 12, Montgomery v Lanarkshire Health Board 2015.

22. See note 12, Montgomery v Lanarkshire Health Board 2015, at paragraph 87.

23. See note 12, Montgomery $v$ Lanarkshire Health Board 2015, at paragraph 108

24. See note 7, Austin, McGuinness 2019.

25. Manson NC, O'Neill, O. Rethinking Informed Consent in Bioethics. Cambridge, UK: Cambridge University Press, 2007.

26. See note 12, Montgomery $v$ Lanarkshire Health Board 2015, at paragraph 90. 


\section{Bioethics Beyond Borders}

27. Heywood R, Miola J. The changing face of pre-operative medical disclosure: Placing the patient at the heart of the matter. Law Quarterly Review 2017;133(Apr):296-321, 311.

28. See note 12, Montgomery $v$ Lanarkshire Health Board 2015, at paragraph 90.

29. See notes 15-17.

30. Community Research. Doctors' Attitudes to Consent and Shared Decision-Making. Full Research Report for the GMC: 2017:32; available at https: / / www.gmc-uk.org/-/media/documents / doctorsattitudes-to-consent-and-shared-decision-making-final-research-report_pdf-72137875.pdf (last accessed 16 Jul 2020).

31. Akkad A, Jackson C, Kenyon S, Dixon-Woods M, Taub N, Habiba M. Patients' perceptions of written consent: Questionnaire study. British Medical Journal 2006;333(7567):528; available at www.bmj.com/ content/bmj/333/7567/528.full.pdf (last accessed 16 Jul 2020); Neary P, Cahill RA, Kirwan WO, Kiely E, Redmond, HP. What a signature adds to the consent process. Surgical Endoscopy 2008;22:2698-99.

32. See note 7, Austin, McGuinness 2019. 